\title{
Chediak-Higashi Syndrome in Accelerated Phase, a Case Report
}

\author{
Artriz R, ${ }^{1 *}$ Pedro $E^{2}$ \\ ${ }^{1}$ Surgeon of the Universidad de los Andes Táchira Extension, Venezula \\ ${ }^{2} 6^{\text {th }}$ year student of medicine at the faculty of the Andes, Táchira extension, Venezula
}

\begin{abstract}
Chediak-Higashi syndrome corresponds to a series of genetic abnormalities in lysosomal transport, of autosomal recessive inheritance, characterized by partial oculocutaneous albinism and recurrent infections, ${ }^{1}$ usually between 7 and 10 years of age the accelerated phase of the disease, where developing hemophagocytic syndrome, given by a set of clinical findings, laboratory and histological studies where phagocytosis is prominent, ${ }^{2}$ with a failure in the regulation of the immune system due to an excessive production of pro-inflammatory cytokines that coexists with a dysfunction of natural killer cells and T lymphocytes, which leads to lethal development. We present a case of a 13-month-old patient, natural and from Pregonero, with a family history of consanguinity, recurrent respiratory infections, and a characteristic phenotype of Chediak-Higashi syndrome, without prior diagnosis or controls for this pathology, who presents with hemophagocytic syndrome leading to its death in 20 days.
\end{abstract}

Keywords: Chediak-Higashi, Hemophagocytic syndrome, Immune dysfunction

\section{Introduction}

Chediak-Higashi syndrome corresponds to a rare, autosomal recessive pathology, which is characterized by partial oculocutaneous albinism, associated with repeated infections, there is a chromosomal alteration at the level of chromosome Xq25, CHS1 gene, located in bands $1 \mathrm{q} 42-43,{ }^{3}$ which leads to a consequent susceptibility to bacterial infections, since there is an alteration at the level of lizosomal transport and chemotaxis of neutrophils and natural killer cells1 are clinically characterized by hypopigmentation of the skin and eyes that are acquiring a coloration silvery, and which may also present: easy-onset ecchymosis, accompanied by hepatomegaly, splenomegaly, and peripheral neuropathies. ${ }^{4}$

Mutations in the CHS1 gene (LYST), located on the long arm of chromosome 1, result in a defect in granule morphogenesis in multiple tissues. This gene encodes a protein called the lysosomal traffic regulator that regulates the synthesis, transport, and fusion of cytoplasmic vesicles. The abnormalities observed in these vesicles result in highly enlarged and non-functional lysosomes, which are identified on cytology as coalescing giant azurophilic granules present particularly in granulocytes and monocytes, but also in fibroblasts, melanocytes, astrocytes, Schwann cells, and hematopoietic cells. These granules are specific for CHS and their presence in peripheral blood or bone marrow granulocytes is the basis for diagnosis. $^{5}$

This syndrome occurs worldwide, without preferential race or sex, its incidence is 1 case per 1,000,000 live new-borns, there is a region of the Venezuelan Andes in which the frequency of cases is notably lower than the locality of town crier who is found in the state of Táchira where this pathology occurs in 1 in 10,000 live newborns, whose historical origin dates back to the presence of indigenous population and Spanish settlers, geographically isolated and with little migratory movements, where intercrossings occurred relatives that possibly led to the expansion of the gene present in some of them, which is known as the founder effect. ${ }^{6}$

In 1943 the first case was described when Moisés Chediak detailed the hematological findings and Ototaka Higashi described the intracytoplasmic granules with peroxidase within lymphocytes

\begin{tabular}{|l|l|}
\hline Quick Response Code: & *Corresponding author: Artriz Rondon, Surgeon of the Universidad de los Andes Táchira \\
Extension, Venezula \\
Received: 06 April, $2021 \quad$ Published: 29 April, 2021 \\
Citation: Artriz R, Pedro E. Chediak-Higashi Syndrome in Accelerated Phase, a Case Report. \\
SOJ Med Clin Case Rep. 2021;1(1):1-3. DOI: 10.53902/SOJMCCR.2021.01.000502
\end{tabular}


and myeloid cells. ${ }^{7}$ The affected granules include lysosomes, melanosomes, platelet dense granules, and cytolytic granules. Before the advent of antibiotics, patients died more often from bacterial infections. Modern antibiotics have reduced, but not eliminated, bacterial infections as a source of death. However, almost invariably, patients now succumb to a lymphocytic infiltrate, termed the accelerated phase. $^{8}$

Some studies seem to correlate the accelerated phase with an Eipsten Barr virus infection, it is known that in this phase a mutation occurs in perforin, a key lytic protein of the granules of cytotoxic T lymphocytes, which suggests that the accelerated phase is the result of defective function of cytotoxic T lymphocytes. The current treatment consists of a bone marrow transplant, since by replacing the hematopoietic system, the infectious component and the accelerated phase are eliminated, and however this does not stop the peripheral neuropathy that occurs as an expression of the defective result of lysosomal function. ${ }^{8}$

The relevance of the present case is given by the place of origin of the girl and her family, as well as her family consanguinity history, which shows how at present the town crier region continues to be a geographical area of importance for this pathology, where inbreeding is still maintained, in addition to being an infant who rapidly develops the accelerated phase.

\section{Clinical Case}

This is an older female infant of 13 months of age, natural and from a town crier, who is brought in by the father for presenting a 5-day evolution of a wet cough and thermal rises quantified at $38.5^{\circ} \mathrm{C}$, which partially subside with the administration of Acetaminophen, after one day of evolution, respiratory distress is associated, so she is brought to the San Cristóbal Hospital where she is assessed and admitted. From a personal history, he presents a family history of consanguinity, with respect to psychomotor development, head control from 4 months, the rest of achievements not reached for the age, parents refer from 6 months to changes in skin pigmentation, repetitive respiratory infections and movements spasmodic in both eyes.
Physical examination reveals a patient in regular general condition, with nutritional deficit (PT:<3DE; TE: $<3$ DE PE: $<3 D E$ ), afebrile, tachypneic, white, thin skin, with generalized macular rash, straight hair with metallic shine, symmetrical eyes, with clear scleras, presence of bidirectional horizontal nystagmus, isochorous pupils, normoreactive to light, with photophobia, the ophthalmological examination shows a pale optic disc, hypo-pigmented fundus, poorly contrasted macula, bilateral anterior cervical and inguinal lymphadenopathies of $1 \mathrm{~cm}$, mobile; Hypoexpansible chest, with slight intercostal pulling, decreased vesicular murmur in both lung fields with crackles, globose abdomen with collateral venous pattern, with hepatomegaly and splenomegaly $5 \mathrm{~cm}$ below the costal margin, at the neurological level hypoactive, reacted to stimuli with decreased tone and sensitivity preserved.

Chest radiographs show bilateral parahilar infiltrates with airborne brochogram, horizontalization of the costal arches compatible with an infectious process such as bronchopneumonia. Given the history and the clinical presentation, pertinent studies are requested in suspected Chediak-Higashi syndrome. In peripheral blood smears he reports histochemical changes in cells, an increase in reticular cells is impressive, which is striking since it is not common to see them in peripheral blood; cytoplasmic inclusions are evidenced in segmented neutrophils and some lymphocytes Figure 1 , Table 1.

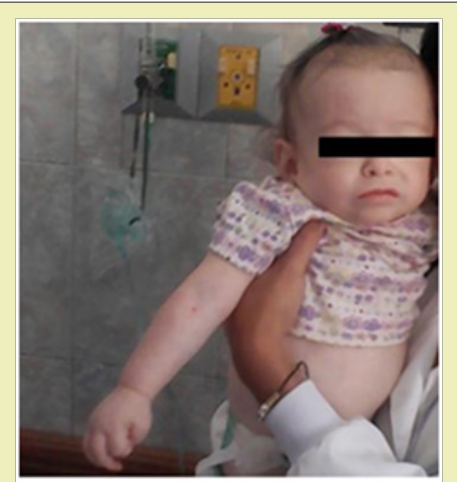

Figure 1: Silver hair is evident, hypopigmented skin, with areas of hyperpigmentation.

Table 1: Laboratorytestsperformedduringhospitalization.

\begin{tabular}{|c|c|c|c|}
\hline Blood count & Day 1 & Day 3 & Day 7 \\
\hline Leukocytes & 2500 & 5200 & 5500 \\
\hline Segmented & $65 \%$ & $70 \%$ & $72 \%$ \\
\hline Lymphocytes & $35 \%$ & $30 \%$ & $28 \%$ \\
\hline Hemoglobin & $6 \mathrm{~g} / \mathrm{dl}$ & $7,2 \mathrm{~g} / \mathrm{dl}$ & $7,5 \mathrm{~g} / \mathrm{dl}$ \\
\hline Hematocrit & $19 \%$ & $22 \%$ & $23 \%$ \\
\hline Platelets & $55.000 / \mathrm{mm}^{3}$ & $22.000 / \mathrm{mm}^{3}$ & $21.000 / \mathrm{mm}^{3}$ \\
\hline Fibrinogen & $150 \mathrm{mg} / \mathrm{dl}$ & $100 \mathrm{mg} / \mathrm{dl}$ & $80 \mathrm{mg} / \mathrm{dl}$ \\
\hline Triglycerides & $310 \mathrm{mg} / \mathrm{dl}$ & $420 \mathrm{mg} / \mathrm{dl}$ & $450 \mathrm{mg} / \mathrm{dl}$ \\
\hline Ferritin & $650 \mathrm{ug} / \mathrm{L}$ & --- & -- \\
\hline Glucose & $167 \mathrm{mg} / \mathrm{dl}$ & $-\cdots$ & -- \\
\hline C-reactive protein & $27 \mathrm{mg} / \mathrm{L}$ & $12 \mathrm{mg} / \mathrm{mL}$ & \\
\hline TORCH & Negative & & \\
\hline
\end{tabular}


Given the phenotype and smear compatible with Chediak-Higashi syndrome criteria, treatment with antibiotics such as ceftriaxone and amikacin were started, later treatment with steroid type dexamatasone was established, transfusion with blood products was carried out: 3 platelet concentrates, 1 cryoprecipitate and 2 globular concentrates. Patient without clinical or paraclinical improvement, with criteria for hemophagocytic syndrome, in poor clinical condition, who undergoes cardiorespiratory arrest and dies 19 days after hospitalization Figure 2-Figure 4.

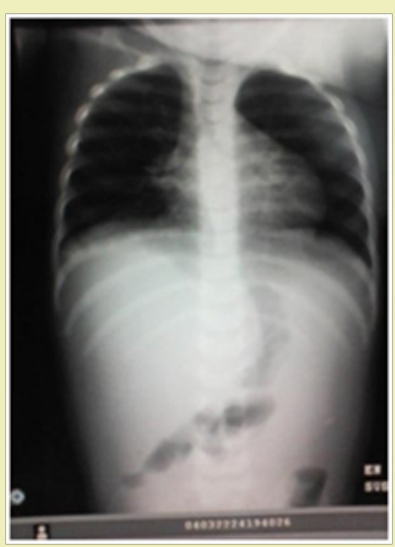

Figure 2: AP X-ray of the abdomen and chest.

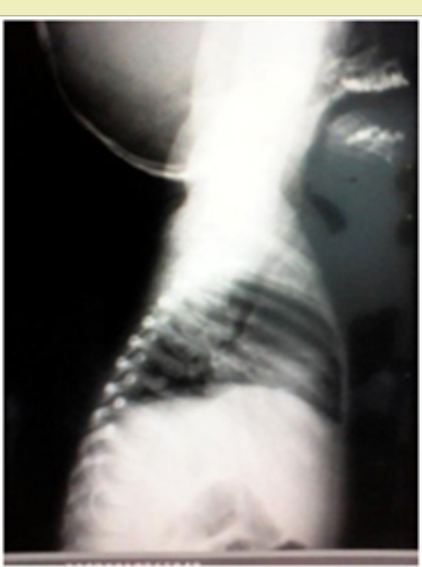

Figure 3: Right lateral chest X-ray.

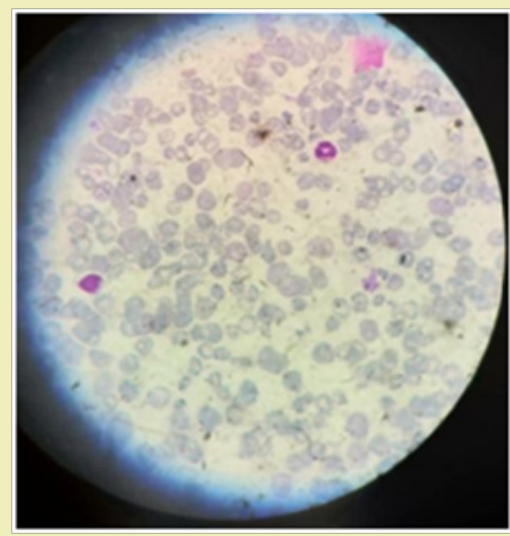

Figure 4: Peripheral blood smear, showing a segmented neutrophil with giant granulations.

\section{Discussion and Conclusion}

Chediak-Higashi syndrome is a rare immunological disorder, with a low incidence worldwide, and a high prevalence in the Venezuelan Andean region, of an autosomal recessive nature, in which consanguinity occurs frequently, ocular hypo-pigmentation can cause photophobia and strabismus and nystagmus are common. ${ }^{6}$ There are alterations at the level of the hair follicle in which there is an abnormal accumulation of pigments that give it a characteristic ash color, patients are usually diagnosed around 5 years of age, generally present recurrent bacterial infections. ${ }^{5}$ These clinical data were observed in the case that is reported, where it is also possible to highlight the young age at which the clinical manifestations of recurrent infections appeared.

Three characteristic phenotypes of this syndrome have been described, the most frequent with 85 to $95 \%$ is the infantile form, which is severe since patients develop an accelerated phase at 7 or 10 years, then they find 10 to $15 \%$ who reach adulthood, develop a mild clinical form, or in whom bone marrow transplantation has been performed, this is accompanied by progressive neurological alterations, in the absence of infections, with a frequent fatal outcome, less than $5 \%$ present hypopigmentation, developmental delay and recurrent infections, reach adolescence without presenting an accelerated phase. ${ }^{6}$ This case corresponds to the infantile phenotype with an early-onset variant of the accelerated phase.

Approximately $85 \%$ of patients with the infantile form of the disease develop the accelerated phase; which can appear in a primary way associated with genetic mutations or secondary as the evolution of neoplasms, infections or autoimmune diseases; characterized by lymphohistiocytic infiltration of the liver, spleen, lymph nodes and bone marrow leading to fever, hepatosplenomegaly, lymphadenopathy, pancytopenia, bone marrow hemophagocytosis, hypertriglyceridaemia and hypofibrinogenemia this is due to disproportionate immunopathological activation ${ }^{5,9}$ leading to disproportionate inflammation..$^{5,9}$

The hemophagocytic syndrome is classified according to the Hemophagocityc Lymphohistiocytosis Study Group of the Histiocyte Society (1991) as primary; which is genetic and family in nature; one that is due to immunological deficit in which the Chediak-Higashi syndrome, Griscelli syndrome and X-linked lymphoproliferative syndrome stand out, and finally in acquired or secondary; which may be linked to infections, neoplasms or immunodeficiencies. ${ }^{10}$

Mortality related to this stage is high, with an estimated survival of 2 months without treatment, for which a high index of suspicion must be had, it is managed with chemotherapy and bone marrow transplantation in primary or refractory cases. The diagnosis of the accelerated phase is established by the detection of genetic mutations PRF1, UNC13D, Munc18-2, Rab27a, STX11, SH2D1A or BIRC4 that would correspond to familial hematophagocytic syndrome, or clinically by the presence of five of the eight diagnostic criteria proposed by the Histiocyte Society ${ }^{9}$ (Table 2). 
Table 2: Diagnostic criteria for hemophagocytic syndrome. ${ }^{9}$

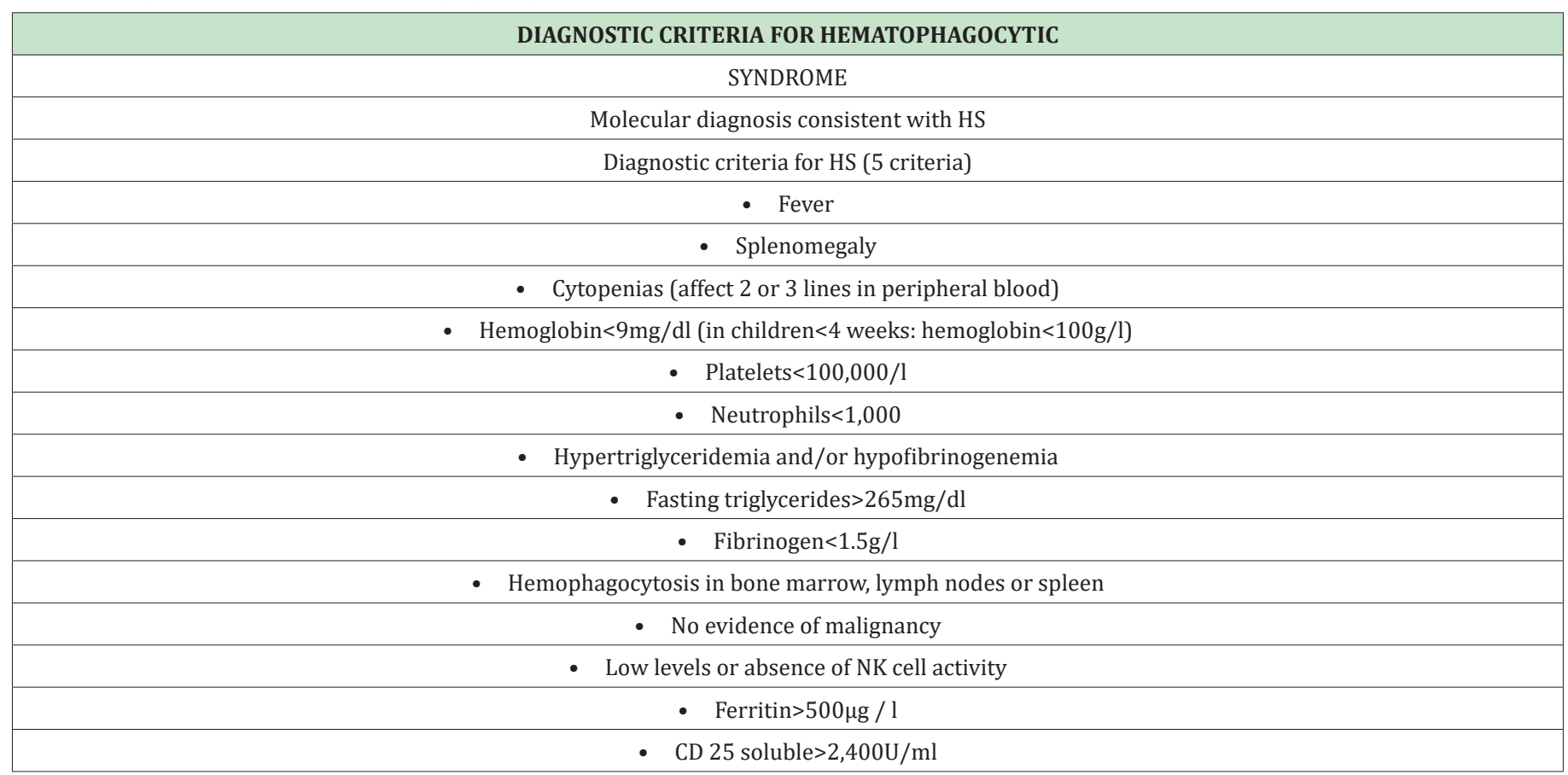

The clinical criteria for hemophagocytic syndrome are met in this patient since 6 clinical criteria were observed, which were: fever, splenomegaly, hemoglobin $6 \mathrm{~g} / \mathrm{dl}$, platelets 55,000 , triglycerides $310 \mathrm{mg} / \mathrm{dl}$, ferritin $650 \mathrm{ug} / \mathrm{L}$. It is important to take into account the possible differential diagnoses that this picture presents, such as Griscelli syndrome in which albinism, silver hair and eyelashes, hepatosplenomegaly, as well as ataxia, seizures, spasticity and immunodeficiency, or Elejalde syndrome occurs, which is autososomal recessive with hypotonia, seizures, mental retardation; silver hair, diplopia nystagmus, blindness without immunodeficiency. ${ }^{4}$

The reported case illustrates the current prevalence of Chediak-Higashi syndrome in the geographical area of the Pregonero, Táchira - Venezuela, hence the importance of maintaining a high suspicion of the clinic presented by the patient, to avoid unnecessary financial expenses, since the Diagnosis is very simple and with inexpensive tests, and treating it early can lead to better survival.

\section{Acknowledgement}

None.

\section{Funding}

None.

\section{Conflicts of interest}

Author declares that there is no conflict of interest.

\section{References}

1. Quero A, Álvarez R, Sánchez L. Chediak-Higashi syndrome, about a clinical case (internet) México. Rev Mex Pediatr. 2012;79(2):105-108.

2. Herrero A, Ramírez, S, Garcia, F, et al. Hemophagocytic syndromes. (INTERNET) 1998 Spain. An Esp Pediatr. 1998;49:230-236.

3. Izzeddin R, Maria Julia Salas M, et al. Chediak-Higashi Syndrome. Report of a Case. Odous Cientifica. 2008;9(1):33-38.

4. Sotelo N, Covarrubias G, Gomez R, et al. Chediak-Higashi syndrome in an infant. A case in accelerated phase. Rev Mex Pediatr. 2007;74(3):113118.

5. Azambujal A, NascimentoII B, Eat S, et al. Four cases of Chédiak-Higashi syndrome. Rev Bras Hematol Hemoter. 2011;33(4).

6. Merino F, Berroeta L, Esparza B, et al. Chediak-higashi syndrome: hypothesis of the origin of the outbreak of the Venezuelan Andes. 1994.

7. Grández N, Rios T, Gonzales A, et al. Chediak-Higashi syndrome: a case report. Peru Folia dermatol. 2009;20(1):19-22.

8. Ward D, Gillian M, Griffiths J, et al. Analysis of the Lysosomal Storage Disease Chediak - Higashi Syndrome. Traffic. 2000;1:816-822.

9. Espinosa K, Garciadiego P, León E. Hemophagocytic syndrome. Current concepts. Gaceta Médica de México. 2013;149:431-417.

10. Alonso A. Hematofagocytic Syndrome in Pediatrics. 